\title{
The Cognitive Errors and Coping Patterns of Child Molesters as Assessed by External Observers: a Pilot Study
}

\author{
Ueli Kramer ${ }^{1}$ and Martin Drapeau*,2
}

\author{
${ }^{1}$ University of Lausanne, Switzerland; ${ }^{2}$ McGill University, Canada
}

\begin{abstract}
Cognitive errors (CE) and coping strategies (CS) are the focus of most cognitive-behavioral treatments for incarcerated child molesters. Several studies have reported differences in CEs and CSs between child molesters and controls. However, the vast majority of these studies assessed cognitive errors and coping using questionnaires, which are known to present a number of important limitations. This pilot study aimed to compare the CEs and CSs of $N=17$ incarcerated child abusers and $N=12$ controls using observer-rated methods, namely the Cognitive Error Rating Scale (CERS; Drapeau et al., 2005) and the Coping Action Pattern Rating Scale (CAPRS; Perry, Drapeau, \& Dunkley, 2005). Results showed that child molesters presented more cognitive errors, in particular positive selective abstraction, and lower coping functioning, such as escape strategies. Treatment and research implications, including the use of observer-rated methods, are discussed.
\end{abstract}

Keywords: Pedophilia, child molesters, child abusers, cognitive errors, coping, cognitive behavioral therapy.

\section{INTRODUCTION}

Cognitive errors (CE) and coping are two important constructs in cognitive behavioral therapy (A.T. Beck, 1976; J. Beck, 1995; Cramer, 1998). CEs, also called cognitive distortions, refer to verbal statements which suggest or indicate ways of evaluating information that reflect biases away from the average or normative evaluation of the same material (Drapeau, Perry, \& Dunkley, 2005), whereas coping includes strategies selected by an individual to respond to and produce an acceptable adaptation to stressors (Skinner, Edge, Altman, \& Sherwood, 2003). Both CEs and coping have been examined in sexual offenders, including child sexual abusers, with the hope of better understanding sexual acting outs and of improving treatment planning and delivery (Geer et al., 2000). For example, previous research on cognitive errors (or cognitive distortions) has shown that sex offenders use self-statements which allow them "to deny, minimize, justify, or rationalize their behavior" (Murphy, 1990, p. 332). Two thirds of sex offenders are said to deny their offense, even after conviction (e.g. Happe \& Auffrey, 1995; Schlank $\&$ Shaw, 1996), or to give distorted accounts of their offense (Segal \& Stermac, 1990). Studies have documented five distorted beliefs in pedophiles, including the belief that children are sexual beings; beliefs regarding the nature of harm (the pedophile minimizes the consequences of his actions by comparing them to the consequences of the actions of another, more violent perpetuator); the belief that the world is a dangerous place (and children are less dangerous); the belief that the deviance is uncontrollable or the result of diverse, external circumstances; and finally, the belief that he, the abuser, is superior to children (i.e. a sense of entitlement) (Gannon, \& Polaschek, 2006; Marziano, Ward, Beech, \& Pattison, 2006; Ward, 2000; Ward \& Keenan, 1999).

*Address correspondence to this author at the ECP - McGill University, 3700 McTavish, Montreal, H3A 1Y2, Quebec, Canada;

E-mail: martin.drapeau@mcgill.ca
Saradjian and Nobus (2003) suggested a stage model of cognitive distortions related to child sexual abuse based on grounded theory analyses of child molesters' discourse. Their findings suggest three main stages, with each stage containing more specific phases or behaviours which can be distorted cognitively. During the pre-offense stage, the abuser may display cognitive distortions in processing or explaining his motivations to offend and his beliefs regarding sexual behaviours involving children, including the beliefs that enable him to reduce his inhibition. During the peri-offense stage, the abuser often denies any harm associated with his fantasies or behaviors and may display distortions which allow him to minimize the potential effects of his behaviors. Finally, during the post-offense stage, the abuser displays guilt-reducing beliefs as well as other distortions which allow him to regain and maintain a positive sense of self.

Concurrent with research on cognitive errors, other studies have examined coping strategies used by pedophiles or child molesters. For example, Neidigh and Tomiko (1991) compared child molesters to controls with no history of sex offense using the Coping Strategy Inventory Questionnaire (Tobin, Horoyd, Reynolds, \& Wigal, 1989). Results showed that pedophiles use more self-devaluing and avoidant coping strategies. According to the authors, these coping strategies are dysfunctional and they contribute to dysphoric mood states and increase the risk of relapse. In another study, Cortoni and Marshall (2001) found that pedophiles use more emotion-focused coping, which involves an emotional response to a problem or stressor. A recent study (Serran, Moulden, Firestone, \& Marshall, 2007) investigated change in coping after a cognitive-behavioral therapy with relapse prevention. The results showed that while no change was found in the subjects' dysfunctional coping strategies after treatment, their level of functional coping increased.

However, the studies above, both in the area of cognitive errors and of coping, all relied on self-report questionnaires. 
Despite their obvious usefulness, self-report measures are known to be vulnerable to various distortions by participants, as well as to present a number of other limitations (Kramer, 2005; Lazarus, 2000). This is particularly true in clinical psychology where participants are often requested to reflect upon their assessment or appraisal of self, others, and events. To date, for example, it remains unclear to what extent an individual's ongoing cognitive activity can be assessed while still providing an accurate picture of its flow (Blankstein \& Segal, 2001). It is also likely that prime specificity varies between questionnaires, or from one item or subscale to the next, hence yielding uneven levels of construct activation and making comparisons between child molesters and controls difficult. This appears to be particularly true in coping research where there is such diversity in the conceptualisations of coping from one questionnaire to the next that comparison between studies is difficult (Skinner et al., 2003).

In response to the above critiques, Drapeau and colleagues (2005) developed an observer rated method to assess cognitive errors, and Perry and colleagues (2005) developed a similar method to assess coping patterns. This pilot study aimed to apply these two methods to child molesters.

\section{METHOD}

\section{Participants}

Semi structured interviews were conducted with 17 male child molesters with a mean age of 38 years $(S D=9)$. During the 50 minute interview, participants were invited to talk about themselves, their problems and difficulties, and their motives for seeking therapy. All subjects had been convicted of sexual abuse on children outside their family and were serving a minimum two-year sentence in a federal penitentiary for their offence ( $M=47$ months; $S D=16$ months). At the time of the study, the subjects had completed the first of a two-step (twice four months) Cognitive-Behavioral and Relapse Prevention Treatment Program. A comparison group of 12 male subjects without any history of child molestation was drawn from a pool of clients who completed four sessions of personal counselling and presented no or moderate psychiatric symptoms, as indicated by a Global Severity Score (Symptom Check-List-90-R; Derogatis, 1994) within psychologically healthy norms. The control subjects were not, and had never been incarcerated. The mean age of the control group participants was 34 years $(S D=11)$. There was no significant difference in age between the participants from the two groups. All participants provided written, informed consent. The 50 minute interviews with the participants from both groups were audio-taped and transcribed according to the method defined by Mergenthaler and Stigler (1998). Because the interviews were not conducted in the same place (a hospital vs. a federal penitentiary), interviewers were not blind to whether the participant was a child molester or non-molester. The project received approval from the Correctional Services of Canada research committee.

\section{Instruments}

The Cognitive Errors Rating Scales (CERS; Drapeau, Perry, \& Dunkley, 2005; French translation by Kramer \& Drapeau, in press) was applied to the interviews by trained raters. The CERS is an observer-rated method to assess cognitive errors in vivo, i.e. as they are reported or used by a subject. The method, which can be applied to the verbatim transcript of any type of interview, assesses 14 different cognitive errors (CEs), based on the works of J. Beck (1995), A. T. Beck (1976) and others. All errors are also scored according to their valence: negative, which reflects a bias toward something bad, poor, weak or otherwise negative, or positive, which reflects a view that is unrealistically positive, strong or successful. Congruent with the works of Lefebvre (1981), CEs can be classified into four higher-order categories, or clusters: fortune-telling, overgeneralizing, selective abstraction, and personalization (see Table 1). Given the sample size, the clusters were used in this study instead of the individual CEs to increase power. An example of a rating is the following statement, taken from an interview with a molester: "I will never have a job once I get out of here". Using the CERS method, this statement was rated as Fortune-Telling - negative valence.

For all computations, relative frequencies were calculated by dividing the raw count of each CE cluster by the number of participant spoken words, by such taking verbal productivity into consideration. This provided a score for each error per 1000 words which was used in the data analysis. Preliminary empirical validation data have been presented by D'Iuso, Blake, Fitzpatrick, and Drapeau (in press) and Lewandowski, D'Iuso, Blake, and Drapeau (in press) for the original English version, and Kramer and Drapeau (in press) for the French version of the method.

The Coping Action Patterns Rating System (CAPRS; Perry, Drapeau, \& Dunkley, 2005; French translation by Kramer \& Drapeau, in press) was also applied to the interviews. The CAPRS is an observer-rated system to assess invivo coping strategies. The method can be applied to any form of transcribed interview. It includes 12 strategies of coping based on the works of Skinner, Edge, Altman, and Sherwood (2003). Relative frequencies are computed for all coping strategies. Furthermore, because each coping strategy can be expressed affectively, behaviourally or cognitively, the overall prevalence of cognitive, affective and behavioural coping, across all different coping strategies rated, is also computed. Based on Skinner and colleagues (2003), an Overall Coping Functioning (OCF) score can be computed to reflect the general level of coping adaptiveness, i.e. the situation is perceived as a challenge, not a threat. An example of a coping rating can be seen in the following statement from a child molester: "I never thought that this (the sexual assault) would have such dramatic consequences". This statement was rated as an Escape strategy, used at a cognitive level.

Preliminary empirical validation data have been presented by D'Iuso and colleagues (in press) and Lewandowski and colleagues (in press) for the original English version, and Kramer and Drapeau (in press) and Kramer and colleagues (in press-a, b, c) for the French version of the method used in this study.

\section{Procedure and Data Analysis}

All transcripts were rated by the first author. Consensus ratings were conducted with fully-trained Master level raters, on 6 of the 29 interviews. While the transcripts of the interviews did not indicate whether the participant was a child molester or not, the content of the interview enabled raters to determine this. Intra-Class Correlation Coefficients ([2,1]; 
Table 1. Cognitive Errors (CEs) Used by Molesters and Controls

\begin{tabular}{|c|c|c|c|c|c|c|}
\hline & \multicolumn{2}{|c|}{ Child Molesters $(N=17)$} & \multicolumn{2}{|c|}{ Controls $(N=12)$} & \multirow[t]{2}{*}{$\mathbf{U}$} & \multirow[t]{2}{*}{ ES } \\
\hline & M & SD & M & SD & & \\
\hline Proportion Negative CEs & .57 & .21 & .83 & .15 & $-3.05 * *$ & 1.38 \\
\hline Proportion Positive CEs & .43 & .20 & .24 & .12 & $-2.57 * *$ & 1.10 \\
\hline Fortune-Telling $/ 1000$ Words & .07 & .09 & .02 & .06 & -1.46 & .63 \\
\hline Over-Generalizing $/ 1000$ words & .06 & .10 & .01 & .04 & -1.68 & .62 \\
\hline Selective Abstraction $_{/ 1000}$ Words & .77 & .56 & .18 & .24 & $-2.90 * *$ & 1.29 \\
\hline Personalization $_{/ 1000 \text { words }}$ & .00 & .00 & .00 & .00 & .00 & .00 \\
\hline Selective Abstraction $/ 1000$ words & .51 & .39 & .43 & .24 & -.62 & .24 \\
\hline Personalization $_{/ 1000 \text { words }}$ & .18 & .15 & .11 & .17 & -1.46 & .44 \\
\hline
\end{tabular}

Note. $p$-values reported are corrected for $\alpha=.05 ; E S=$ effect size. $* p<.05 ; * * p<.01$.

Shrout \& Fleiss, 1979) were calculated to determine interrater reliability. Non-parametric tests were used (MannWhitney's U) to test between-group differences. Effect sizes (d) were computed for all comparisons.

\section{RESULTS}

\section{Cognitive Errors}

Inter-rater reliability in assessing the CEs was good with Intra-class coefficients $(2,1)$ between .69 and $.87(M=.77$; $S D=.08)$. U-tests showed that child molesters display more CEs per 1000 words than controls, and that the child molesters' proportion of positive CEs is greater than the controls' (see Table 1). Furthermore, U-tests with Bonferroni corrections ( $p=.01$ for $\alpha=.05$ ) show that positive selective abstraction is over 4 times more prevalent in the molesters. No other significant difference was found.

\section{Coping Strategies}

Inter-rater reliability in assessing the coping strategies was good with Intra-class coefficients $(2,1)$ between .73 and $.96(M=.86 ; S D=.09)$. As can be seen in Table 2, the Overall Coping Functioning (OCF) score was lower in the child molesters, thus indicating less adaptiveness in their coping strategies. When examining the individual coping strategies, a significant effect following Bonferroni corrections was found only for escape strategies. Escape was over two times more prevalent in the abuser group. Results also showed that behavioural, but not affective or cognitive, coping strategies are more prevalent in pedophiles.

\section{DISCUSSION}

Results showed more positive cognitive errors in child molesters, in particular selective abstraction. This category includes errors in which a negative part of reality is ignored, denied or minimized to enable the subject to maintain a positive view of the world, the self and the future. This may enable the abuser to deny the consequences of the abuse (see also Saradjian, \& Nobus, 2003). While this was not tested here, it is likely that such cognitive processes contribute to relapse. As suggested by theories on cognitive deconstruction (Baumeister, 1990; see also Gannon, \& Polaschek, 2006), discounting the negative, a CE often described in the clinical literature, contributes to diminishing a subject's sense of responsibility for his or her actions and leads to disengagement from cognitive processing and to offensesupportive beliefs. Discounting the negative is considered to be a form of positive selective abstraction in the CERS method because it involves dismissing or disqualifying information that is negative, thus keeping only positive information as true, relevant or important.

Overall, coping in child molesters was characterized by a lower level of general adaptiveness as indicated by a significantly lower OCF score. This suggests that the molesters' cognitive processing of the world around them is reflected in their coping strategies; perceiving the world as a dangerous place was one of the five distorted beliefs found in pedophiles by Segal and Stermac (1990). Concurrent with this, our results, while preliminary, suggest that stressors are mostly perceived as threats, not challenges. More specifically, congruent with findings obtained by Neidigh and Tomiko (1991) using a self-report questionnaire, escape appeared to be a specific coping process in child molesters which may contribute to short-term adjustment in these individuals, but which may also potentially prevent long-term successful adaptation (see Skinner et al., 2003). Moreover, it appears that behavioral manifestations of coping were more prevalent in child molesters than in the control males, suggesting difficulty in adjusting to stressors at an affective or cognitive level, and a tendency to cope with internal or ex- 
Table 2. Between-Group Differences in Coping Strategies

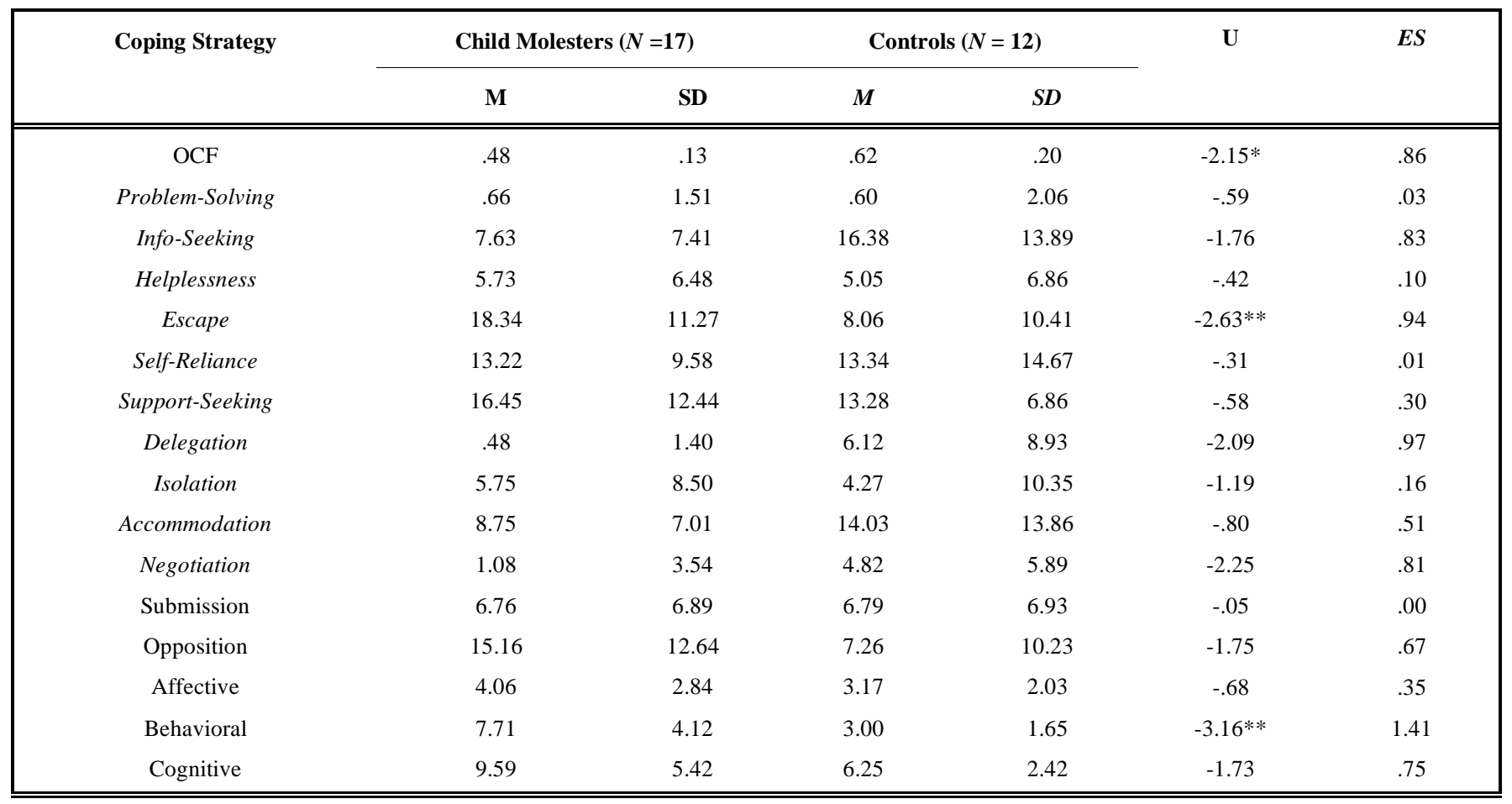

${ }^{*} p<0.05 ; * * p<.0 .01 ; * * * p<.0 .001$

ternal stressors behaviourally. This finding is contrary to that of Cortoni and Marshall (2001) who found, using a questionnaire, that child abusers use more emotion-focused coping. While a number of differences between the two studies could explain this disparity, a major difference was that Cortoni and Marshall focused on sex as a coping strategy, not on all possible coping schemes. Taken together, the two studies may suggest that while sex could serve as an affective coping strategy, the other strategies used by the abusers tend to be mostly behavioural. Sex may serve as a coping mechanism to deal with loneliness and intimacy problems because it may create the illusion of an affective connection to another. However, it appears to be one of the few areas where the coping strategy has affective components.

Several limitations to this pilot study need to be acknowledged. The sample size is small, resulting in limited statistical power. The non-directiveness of the clinical interviews was an advantage in many regards, but it also meant, despite efforts from the interviewer, that interviewees did not equally focus on the problems that led them to seeking help and on treatment related issues. Nonetheless, the use of observer-rated methods sheds a different light on the functioning of child molesters and such research on cognitive errors and coping in abusers needs to be carried further, with the aim of adapting psychotherapeutic interventions to the abusers' functioning and needs. Cognitive restructuring techniques may be useful to increase the subjects' awareness of their cognitive deficits and vulnerabilities and focus on improving ways of coping with stressors, as some coping strategies represent a vulnerability factor that needs to be taken into account for prognosis and treatment planning and delivery. As such, relapse-programs for child molesters could be tailored to the individual profile of the abusers in terms of cognitive errors and coping patterns. In particular, the long-term study of psychotherapy would lead to a better understanding of the nature and the change over time of CEs and coping strategies in the treatment of child molesters. Until the different aspects of the abusers' functioning are examined from different perspectives, our understanding of what leads to the sexual acting out and of what is required to effectively treat them remains incomplete.

\section{ACKNOWLEDGMENTS}

The authors thank Daniela Dremmel and Natalia Pasandin for the reliability ratings.

\section{REFERENCES}

Baumeister, R. F. (1990). Anxiety and deconstruction: On escaping the self. In: Olson, J. M. \& Zanna, M. P. (Eds.), Self-Inference Processes: The Ontario Symposium, vol. 6 (pp. 359-291). Hillsdale, NJ: Erlbaum.

Beck, A. T. (1976). Cognitive Therapy and the Emotional Disorders. New York: International Universities Press.

Beck, J. S. (1995). Cognitive Therapy. Basics and Beyond. New York: Guilford.

Blankstein, K. R, \& Segal, Z. V. (2001). Cognitive assessment: issues and methods. In Dobson, K. S. (Ed.). Handbook of cognitive-behavioral therapies (2nd ed.). (pp. 40-85). New York, NY: Guilford Press.

Cortoni, F. A., \& Marshall, W. L. (2001). Sex as a coping strategy and its relationship to juvenile sexual history and intimacy in sexual offenders. Sexual Abuse: A Journal of Research and Treatment, 8, 27-43.

Cramer, P. (1998). Coping and Defense Mechanisms: What's the difference? Journal of Personality, 66(6), 919-946.

Derogatis, L. R. (1994). Symptom Checklist-90-Revised: Administration scoring and procedures Manual (3rd ed.). Minneapolis MN: National Computers Systems.

D’Iuso, D., Blake, E., Fitzpatrick, M., \& Drapeau, M. (In press). Cognitive errors, coping patterns, and the therapeutic alliance: a study of insession process. Counseling and Psychotherapy Research. 
Drapeau, M., Perry, J. C., \& Dunkley, D. (2005). The Cognitive Errors rating system. McGill University: Author.

Gannon, T. A., \& Polaschek, D. L. L. (2006). Cognitive distortions in child molesters : A re-examination of key theories and research. Clinical Psychology Review, 26, 1000-1019.

Geer, J. H., Estupinan, L. A., \& Manguno-Mire, G. M. (2000). Empathy, social skills, and other relevant cognitive processes in rapists and child molesters. Aggression and Violent Behavior, 5(1), 99-126.

Happel, R. M., \& Auffrey, J. J. (1995). Sex offender assessment: Interrupting the dance of denial. American Journal of Forensic Psychology, 13(2), 5-22.

Kramer, U. (2005). La mesure du coping : une revue clinique des instruments. The measure of coping : a clinical review of instruments. Journal de Thérapie Comportementale et Cognitive, 15(2), 46-54.

Kramer, U. (2006). Cognitive Errors and Coping Action Patterns: New Strategies of Conceptualization. Poster presented at the Herbstakademie. October, Ascona, Switzerland.

Kramer, U., de Roten, Y., Michel, L., \& Despland, J.-N. (in press-a). Early change of defense mechanisms and coping in short-term dynamic psychotherapy: relations with symptoms and alliance. Clinical Psychology and Psychotherapy.

Kramer, U., \& Drapeau, M. (in press). Validation de la version française des échelles de codage du coping et des erreurs cognitives (CE-CAP) sur une population non-clinique Validation studies of the French Version of the Rating Scales on Coping and Cognitive Errors (CE$\mathrm{CAP})$ on a community sample. Annales Médico-Psychologiques.

Kramer, U., Drapeau, M., \& Bodenmann, G. (in press-b). Too much Positive Thinking? Cognitive Errors in Bipolar Affective Disorder, Symptoms and Therapeutic Alliance. The Cognitive Behaviour Therapist.

Kramer, U., Drapeau, M., Khazaal, Y., \& Bodenmann, G. (2009). Coping Specificities in Bipolar Affective Disorder: Relation with Symptom Symptom Evolution and Therapeutic Alliance. German Journal of Psychiatry, 12, 19-27.

Lazarus, R. S. (2000). Toward better research on stress and coping. American Psychologist, 55(6), 665-673.

Lefebvre, M. F. (1981). Cognitive distortion and cognitive errors in depressed psychiatric and low back pain patients. Journal of Consulting and Clinical Psychology, 49, 517-525.

Lewandowski, M., D’Iuso, D., Blake, E., \& Drapeau, M. (In press). Cognitive errors and coping strategies and their relation to client involvement and experiencing. Counseling \& Psychotherapy Research.
Marshall, W. L., Anderson, D., \& Fernandez, Y. M. (1999). Cognitive behavioral treatment of sexual offenders. Chichester, England: John Wiley \& Sons.

Marziano, V., Ward, T., Beech, A. R., \& Pattison, P. (2006). Identification of five fundamental implicit theories underlying cognitive distortions in child abusers: A preliminary study. Psychology, Crime and Law, 12(1), 97-105.

Mergenthaler, E., \& Stigler, M. (1997). Règles de transcription pour la recherche en psychothérapie (adaptation française) [Transcribing rules for Psychotherapy Research (French adaptation)]. Psychothérapies, 17(2), 97-103.

Murphy, W. D. (1990). Assessment and modification of cognitive distortions in sex offenders. In Marshall, W. L. Laws, D. R. \& Barbaree, H. E. (Eds.), Handbook of sexual assault: Issues, theories, and treatment of the offender (pp. 331-342). NY: Plenum.

Neidigh, L., \& Tomiko, R. (1991). The coping strategies of child sexual abusers. Journal of Sex Education \& Therapy, 17, 103-110.

Perry, J. C., Drapeau, M., Dunkley, D., \& Blake, E. (2005). The Coping Action Patterns rating system. Montréal : McGill University.

Saradjian, A., \& Nobus, D. (2003). Cognitive distortions of Religious professionals who sexually abuse children. Journal of Interpersonal Violence, 18(8), 905-925.

Schlank, A. M., \& Shaw, T. (1996). Treating sexual offenders who deny their guilt: apilot study. Sexual Abuse: A Journal of Research and Treatment, 8, 17-23.

Segal, Z. V., \& Stermac, L. E. (1990). The role of cognitions in sexual assault. In Marshall, W. L. Laws, D. R. \& Barbaree H. E. (Eds.), Handbook of sexual assault: Issues, theories and treatment of the offender (pp. 161-174). New York: Plenum.

Serran, G. A., Moulden, H., Firestone, P., \& Marshall, W. L. (2007). Changes in coping following treatment for child molesters. Journal of Interpersonal Violence, 22(9), 1199-1210.

Shrout, P. E., \& Fleiss, J. L. (1979). Intraclass correlation: uses in assessing rater reliability. Psychological Bulletin, 86(2), 420-428.

Skinner, E. A., Edge, K., Altman, J., \& Sherwood, H. (2003). Searching for the structure of coping: a review and critique of category systems for classifying ways of coping. Psychological Bulletin, 129, 216269.

Tobin, D. L., Holroyd, K. A., Reynolds, R. V., \& Wigal, J. K. (1989). The hierarchical factor structure of the coping strategies inventory. Cognitive Therapy and Research, 13, 343-361.

Ward, T. (2000). Sexual offenders' cognitive distortions as implicit theories. Aggression and Violent Behavior, 5, 491-507.

Ward, T., \& Keenan, T. (1999). Child molesters' implicit theories. Journal of Interpersonal Violence, 14, 821-838.

(C) Kramer and Drapeau; Licensee Bentham Open.

This is an open access article licensed under the terms of the Creative Commons Attribution Non-Commercial License (http://creativecommons.org/licenses/by-nc/3.0/) which permits unrestricted, non-commercial use, distribution and reproduction in any medium, provided the work is properly cited. 